\title{
On Balanced Repeated Measurements Designs
}

Shakeel Ahmad Mir

Head Division of Agric. Statistics, India

mir_98@msn.com

\begin{abstract}
Repeated Measurements designs are concerned with scientific experiments in which each experimental unit is assigned more than once to a treatment either different or identical. This class of designs has the property that the unbiased estimators for elementary contrasts among direct and residual effects are obtainable. Afsarinejad (1983) provided a method of constructing balanced Minimal Repeated Measurements designs $\mathrm{p}<\mathrm{t}$, when $\mathrm{t}$ is an odd or prime power, one or more than one treatment may occur more than once in some sequences and designs so constructed no longer remain uniform in periods. In this paper an attempt has been made to provide a new method to overcome this drawback. Specifically, two cases have been considered $\mathrm{RM}[\mathrm{t}, \mathrm{t}(\mathrm{t}-\mathrm{t}) /(\mathrm{p}-1), \mathrm{p}], \lambda_{2}=1$ for balanced minimal repeated measurements designs and $\mathrm{RM}[\mathrm{t}, 2 \mathrm{t}(\mathrm{t}-\mathrm{t}) /(\mathrm{p}-1), \mathrm{p}], \lambda_{2}=2$ for balanced repeated measurements designs. In addition, a method has been provided for constructing extra-balanced minimal designs for special case $\mathrm{RM}\left[\mathrm{t}, \mathrm{t}^{2} /(\mathrm{p}-1), \mathrm{p}\right], \lambda_{2}=1$.
\end{abstract}

Keywords and Phrases: Balanced Minimal Repeated Measurements design; Extrabalanced Repeated Measurements design; Uniform Repeated Measurements design; Cross-over designs; direct effects; residual effects.

\section{Introduction}

An experimental design in which experimental units are used repeatedly by exposing them to a sequence of different or identical treatments is called Repeated Measurements design (RM designs). In Repeated Measurements designs we administer t treatments during $\mathrm{p}$ periods to $\mathrm{n}$ experimental units and these designs are usually denoted as RM (t, $\mathrm{n}, \mathrm{p}$ ). Repeated Measurements designs find application in many branches of scientific inquiry, such as agriculture, animal husbandry, food science, biology, market research, medicine, pharmacology, social engineering, etc.

In some experiments, the nature of treatments or the experimental units may generate responses, which are free from residual effects. Some times the experimenter can introduce a rest period and allow the experimental units to even up. As many researchers such as Cochran and Cox (1986), Sheeh and Bross (1961) Westlake (1974) Afsarinejad (1989) and Afsarinejad (1990) have pointed out that, it is not always possible or desirable to use such a design. If residual effects exist, then the methods applicable to conventional designs are not valid. The experimenter has to design the experiment such that unbiased estimator for elementary contrasts among direct and residual effects can be obtained.

\section{Notations, Definitions and Terminology}

The following notations and definitions due to Hedayat and Afsarinejad (1975) and (1978) provide a useful language in which to express the results of this paper.

In the rest of this paper by an RM (t, n, p) design, we mean a Repeated Measurements design based on $t$ treatments, $n$ experimental units each being used for $t$ distinct 
treatments in $\mathrm{p}$ periods. Let the rows correspond to periods and columns to experimental units. The total number of observations in this setup are "pn". For analysis of these pn observations, we assume the fixed effects model:

$$
\begin{aligned}
& y_{i j}=\mu+\alpha_{i}+\beta_{j}+\tau_{d(i, j) \tau}+\rho_{d(i-1, j)}+\varepsilon_{i j} \\
& \mathrm{i}=1,2,3, \ldots \ldots \ldots, \mathrm{p} \text { and } \mathrm{j}=1,2,3, \ldots \ldots \ldots, \mathrm{n}
\end{aligned}
$$

Where

$y_{i j}$ is the response of the $j$ th experimental unit in the ith period

$\alpha_{i}$ is the ith period effect

$\boldsymbol{\beta}_{j}$ is the $j$ th experimental unit effect

$\tau_{d(i, j)}$ is direct effect of $\mathrm{d}(\mathrm{i}, \mathrm{j})$ treatment

$\rho_{d(i-1, j)}$ is the residual effect of $\mathrm{d}(\mathrm{i}, \mathrm{j})$ treatment and

$\varepsilon_{i j}$ is the random error normally distributed with mean zero and variance $\sigma^{2}$

Definition 2.1. A design d in RM ( $\mathrm{t}, \mathrm{n}, \mathrm{p})$ is said to be uniform on the experimental units if $d(i, j) \neq d(i, j), i \neq i$ for all $j$.

Definition 2.2. A design d in RM ( $\mathrm{t}, \mathrm{n}, \mathrm{p})$ is said to be uniform on the periods if, in each period, $d$ assigns the same number of experimental units to each treatment.

Definition 2.3. A design $\mathrm{d}$ in $\mathrm{RM}(\mathrm{t}, \mathrm{n}, \mathrm{p})$ is said to be uniform if it is uniform on both the experimental units and periods.

Definition 2.4. A RM (t, n, p) design is said to be balanced with respect to sets of direct and residual effects if (i) each treatment is tested equally frequently $\lambda_{1}$ times in each period, (ii) in the order of application each treatment is preceded by each other treatment equally frequently $\lambda_{2}$ times.

In balanced RM (t, n, p) design the following relations hold for design parameters $t, n, p$, $\lambda_{1}$ and $\lambda_{2}$

$$
\mathrm{n}=\lambda_{1} \mathrm{t}, \quad \mathrm{n}(\mathrm{p}-1)=\lambda_{2} \mathrm{t}(\mathrm{t}-1)
$$

For given $\mathrm{t}$ and $\mathrm{p}$ the above conditions lead to the following definition (Patterson, 1952)

Definition 2.5. For the given $\mathrm{t}$ and $\mathrm{p}$, a balanced $\mathrm{RM}(\mathrm{t}, \mathrm{n}, \mathrm{p})$ design is said to be minimal if

$$
\mathrm{n}=\mathrm{t}(\mathrm{t}-1) /(\mathrm{p}-1) \text { and }(\mathrm{t}-1) /(\mathrm{p}-1)=\lambda_{1} \text { is an integer }
$$

The following theorem which was first proved by Houston (1966)

Theorem 2.1. A balanced minimal repeated measurements design satisfying the equations (2.1) and $p<t$ exists if $\lambda_{1} p \times t$ tables can be constructed cyclically from $\lambda_{1} p \times$ 1 columns with the property that the differences between pairs adjacent elements of their first column are distinct and nonzero $(\bmod t)$.

Definition 2.6. Afsarinejad (1983) defined Extra-balanced Repeated Measurement designs as the extension of balanced RM design in which each treatment is allowed to be 
immediately preceded by itself as well. So for the Extra-balanced Repeated Measurements design amongst $\mathrm{t}, \mathrm{n}, \mathrm{p}, \lambda_{1}, \lambda_{2}$ the following relations hold:

$$
\mathrm{n}=\lambda_{1} \mathrm{t}, \quad \mathrm{n}(\mathrm{p}-1)=\lambda_{2} \mathrm{t}^{2}
$$

Definition 2.7. For every $\mathrm{t}$ and $\mathrm{p}$ an Extra-balanced Repeated Measurements design is minimal if $\mathrm{n}=\mathrm{t}^{2} /(\mathrm{p}-1)$ and $\mathrm{t} /(\mathrm{p}-1)=\lambda_{1}$ is an integer

Theorem 2.2. An Extra-balanced Minimal Repeated Measurements design satisfying the equations (2.2) and $p<t$ exists if $\lambda_{1} p \times t$ tables can be constructed cyclically from $\lambda_{1}$ $p \times 1$ columns with the property that the differences between pairs adjacent elements of their first column are distinct $(\bmod t)$.

The class of balanced minimal RM (t, n, p) design can be divided into two families. Family (I), where $\mathrm{t}=\mathrm{p}$ and Family (II), where $\mathrm{p}<\mathrm{t}$.

Family (I) $p=t$ :

For this family $\lambda_{1}$ achieves its minimum value viz., 1 . Note that for this family $n=t$ and each of its number can be represented by an RM $(t, t, t)$ design.

Williams (1949) introduced and constructed minimal RM designs for those experimental situations in which the number of periods is equal to the number of treatments whenever the number of treatments is even. Houston (1966) showed that it is impossible to construct a balanced minimal RM design based on a cyclic group when the number of treatments is odd. Mendelsohn (1968) constructed a balanced minimal RM design for 21 treatments based on non-cyclic group. Bradley (1953), Gordon (1961), Sheehe and Brass (1961) have all considered and constructed the balanced minimal RM (t, t, t) for all even t's. Mir et al., (2005) introduced the balanced minimal Repeated Measurements designs uniform on periods, when the number of periods is equal to the number of treatments whenever the number of treatments is odd. Mir et al., (2008) constructed a series of balanced minimal Repeated Measurements designs when $t$ is an odd prime or prime power.

Our main concern is to study Family (II), where p < t: Patterson (1952) considered and constructed balance minimal Repeated Measurements designs whenever $\mathrm{p}<\mathrm{t}$. Patterson \& Lucas (1962) gave a catalogue of Repeated Measurements designs in which the number of periods is equal to or less than the number of treatments. Atkinson (1961), Davis \& Hall (1969), Hedayat \& Afsarinejad (1975), Constantine \& Hedayat (1982 ), Afsarinejad (1983), Gharde (2007), Dey et al., (1995) and Varghese \& Sharma (2000) studied the cross-over designs in the presence of first order residual effects. Stufken (1991) constructed some families of optimal and efficient repeated measurements designs. Hedayat and Young (2004) studied universal optimality for selected crossover designs. Sharma et al., (2003) have constructed some minimal balanced Repeated Measurements designs for the situations whenever $\mathrm{p}<\mathrm{t}$. Iqbal et al., (2009) constructed Circular strongly balanced repeated measurements designs and again Iqbal et al., (2010) studied Circular first- and second-order strongly balanced repeated measurements designs. Mir et al., (2009) introduced and constructed a new class of balanced Repeated Measurements designs for two-crop system involving two different sets of treatments. 
Afsarinejad (1983) have given a construction method for balanced minimal Repeated Measurements design when $t$ is an odd number. But this method has a drawback that when the number of treatments $t$ is an odd prime or prime power, one or more than one treatment occurs more than once in any sequence and thereby design no longer remain uniform. In this paper an attempt has been made to provide a new method to overcome this drawback. Specifically, two cases have been considered

$\mathrm{RM}[\mathrm{t}, \mathrm{t}(\mathrm{t}-\mathrm{t}) /(\mathrm{p}-1), \mathrm{p}], \lambda_{2}=1$ for balanced minimal repeated measurements designs and $\mathrm{RM}[\mathrm{t}, 2 \mathrm{t}(\mathrm{t}-\mathrm{t}) /(\mathrm{p}-1), \mathrm{p}], \lambda_{2}=2$ for balanced repeated measurements designs. In addition, an approach has been provided for constructing extra-balanced minimal designs for special case $\mathrm{RM}\left[\mathrm{t}, \mathrm{t}^{2} /(\mathrm{p}-1), \mathrm{p}\right], \lambda_{2}=1$.

\section{Construction of Balanced minimal Repeated Measurements designs}

\section{1: $R M[t, t(t-1) /(p-1), p], \lambda_{2}=1$}

For every t that is prime or prime power the design $\mathrm{RM}[\mathrm{t}, \mathrm{t}(\mathrm{t}-1) /(\mathrm{p}-1), \mathrm{p}], \lambda_{2}=1$ can always be constructed where (t-1) / (p-1) is an integer, wherein no treatment occur more than once in any sequence.

Afsarinejad (1983) have given a construction method for balanced minimal Repeated Measurements design when $t$ is an odd number. But this method has a drawback that when the number of treatments $t$ is an odd prime or prime power, one or more than one treatment occurs more than once in some sequences and thereby designs no longer remain uniform over periods. For example $\operatorname{RM}(7,21,3)$, the initial sequences obtained for this design by the method given by Afsarinejad (1983) is reproduced below in Table No.3.1

Table No. 3.1: $\lambda 1=3$ Initial Sequences

\begin{tabular}{|l|lll|}
\hline \multirow{3}{*}{ Elements } & \multicolumn{3}{|c|}{ Sequences no. } \\
\cline { 2 - 4 } & I & II & III \\
\cline { 2 - 4 } & 1 & $\mathbf{3}$ & 3 \\
& 7 & 5 & 7 \\
& 3 & $\mathbf{3}$ & 1 \\
\hline
\end{tabular}

It is evident that on developing above initial sequences treatments will be repeated more than once. So new method of construction is introduced which does not suffer from this drawback.

Theorem 3.1: Balanced minimal RM [t, $t(t-1) /(p-1), p], \lambda_{2}=1$ where $t$ is a prime or prime power and $(t-1) /(p-1)$ is an integer can always be constructed.

Construction Method 3.1: Let $\mathrm{t}$ be a prime or prime power, say $\mathrm{t}=\mathrm{S}^{\mathrm{h}}$, where $\mathrm{S}$ is a prime number and $\mathrm{h}$ is an integer. Let $(\mathrm{t}-1) \equiv 0 \bmod (\mathrm{p}-1)$ i.e. $(\mathrm{t}-1) /(\mathrm{p}-1)=\lambda_{1}$ is an integer. Let $\mathrm{x}$ is the primitive root of Gloise Field GF (t) and we denote the elements of GF (t) as $\alpha_{0}=0, \alpha_{1}=x^{0}, \alpha_{2}=x^{1}, \ldots, \alpha_{1}=x^{1-1}, \ldots \ldots, \alpha_{t-1}=x^{t-2}$ 
Let $\mathrm{RM}[\mathrm{t}, \mathrm{t}(\mathrm{t}-1) /(\mathrm{p}-1), \mathrm{p}]$ consisting of $\mathrm{n}=\mathrm{t}(\mathrm{t}-1) /(\mathrm{p}-1)$ sequences each of $\mathrm{p}$ elements (treatments) be represented as $\mathrm{p} x \mathrm{n}$ array say $\mathrm{A}$ of $\mathrm{p}$ rows $\mathrm{n}$ columns. Let the $\mathrm{p}$ rows be numbered as $1,2,3, \ldots \ldots$, pth row and $\mathrm{n}=\lambda_{1} \mathrm{t}$ column be numbered as $0,1,2,3, \ldots, \mathrm{t}-1$, $\mathrm{t}-0, \quad \mathrm{t}+1, \quad \mathrm{t}+2, \quad \ldots \ldots, \quad \mathrm{t}+(\mathrm{t}-1), \ldots, \quad(\mathrm{k}-1) \mathrm{t}+0, \quad(\mathrm{k}-1) \mathrm{t}+1, \ldots, \quad(\mathrm{k}-1) \mathrm{t}+(\mathrm{t}-1), \ldots, \quad\left(\lambda_{1}-1\right) \mathrm{t}+0$, $\left(\lambda_{1}-1\right) \mathrm{t}+1, \ldots,\left(\lambda_{1}-1\right) \mathrm{t}+(\mathrm{t}-1)$.

The entries of the array A will be the treatments of the experiment. The element in the ith row and mth column, will be an element of GF (t) equal to

$$
\left[\alpha_{\mathrm{i}}\right]\left[\alpha_{(\mathrm{k}-1)(\mathrm{p}-1)+1}\right]+\alpha_{\mathrm{j}}=\left[\mathrm{x}^{\mathrm{i}-1}\right]\left[\mathrm{x}^{(\mathrm{k}-1)(\mathrm{p}-1)}\right]+\alpha_{\mathrm{j}}
$$

where $\mathrm{m}=(\mathrm{k}-1) \mathrm{t}+\mathrm{j}, \mathrm{i}=1,2,3, \ldots . ., \mathrm{p} ; \mathrm{j}=0,1,2,3, \ldots \ldots, \mathrm{t}-1 ;$ and $\mathrm{k}=1,2,3, \ldots, \lambda_{1}$.

The array $\mathrm{A}$ is a balanced minimal $\mathrm{RM}[\mathrm{t}, \mathrm{t}(\mathrm{t}-1) /(\mathrm{p}-1), \mathrm{p}]$, where

$\lambda_{1}=(\mathrm{t}-1) /(\mathrm{p}-1)$ and $\lambda_{2}=1$ according to the definition of Hedayat and Afsarinejad (1975).

The construction method 3.1 is illustrated by the following example 3.1

Example 3.1. Let $\mathrm{t}=7$ (prime number) and $\mathrm{p}=3$. Then the above procedure produces balanced minimal RM $(7,21,3), \lambda_{2}=1$ as shown in Table 3.2 and the design so obtained is reproduced in the Table 3.2

Table No. 3.2: $\quad$ Balanced minimal $\operatorname{RM}(7,21,3), \lambda_{1}=3, \lambda_{2}=1$

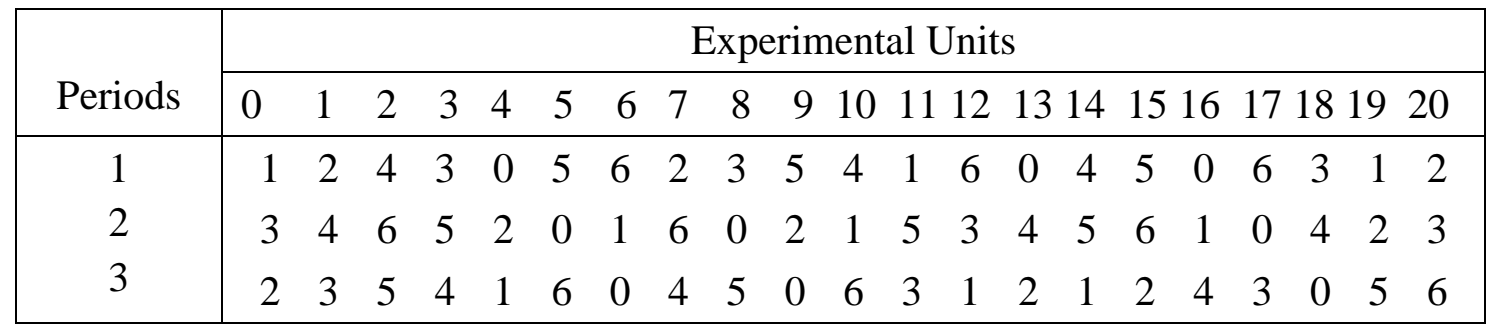

Example3.2. Let $\mathrm{t}=9$ (prime power) and $\mathrm{p}=5$. Then the above procedure produces balanced minimal RM $(9,18,5), \lambda_{2}=1$ and the design so obtained is reproduced in the Table 3.3

Table No. 3.3: Balanced minimal $\operatorname{RM}(9,18,5), \lambda_{1}=2, \lambda_{2}=1$

\begin{tabular}{|c|ccccccccccccccccccccc|}
\hline & \multicolumn{11}{|c|}{ Periods } & \multicolumn{1110}{|c|}{} & 0 & 1 & 2 & 3 & 4 & 5 & 6 & 7 & 8 & 9 & 10 & 11 & 12 & 13 & 14 & 15 & 16 & 17 \\
\hline 1 & 1 & 5 & 3 & 8 & 7 & 0 & 4 & 6 & 2 & 5 & 0 & 8 & 2 & 6 & 1 & 7 & 4 & 3 \\
2 & 2 & 3 & 6 & 4 & 1 & 8 & 0 & 5 & 7 & 6 & 4 & 0 & 1 & 3 & 7 & 2 & 8 & 5 \\
3 & 3 & 8 & 4 & 7 & 5 & 2 & 1 & 0 & 6 & 7 & 6 & 5 & 0 & 2 & 4 & 8 & 3 & 1 \\
4 & 4 & 7 & 1 & 5 & 8 & 6 & 3 & 2 & 0 & 8 & 2 & 7 & 6 & 0 & 3 & 5 & 1 & 4 \\
5 & 5 & 0 & 8 & 2 & 6 & 1 & 7 & 4 & 3 & 1 & 5 & 3 & 8 & 7 & 0 & 4 & 6 & 2 \\
\hline
\end{tabular}




\section{2: $\mathrm{RM}[\mathrm{t}, 2 \mathrm{t}(\mathrm{t}-1) /(\mathrm{p}-1), \mathrm{p}], \lambda_{2}=2$}

Theorem 3.2: Balanced $\mathrm{RM}[\mathrm{t}, 2 \mathrm{t}(\mathrm{t}-1) /(\mathrm{p}-1)$, $\mathrm{p}]$ can always be constructed when $\mathrm{t}$ is a prime or prime power and $2(\mathrm{t}-1) /(\mathrm{p}-1)=\lambda_{1}$ is an integer with $\lambda_{2}=2$.

Construction Method 3.2: Let $\mathrm{t}$ be a prime or prime power of the form $\mathrm{t}=\mathrm{S}^{\mathrm{h}}$, where $\mathrm{S}$ is a prime number and $\mathrm{h}$ is an integer. Let the number of rows (periods) $\mathrm{p}$ be such that $2(\mathrm{t}-1) /(\mathrm{p}-1)$ is an integer. Then an array A of $\mathrm{p}$ rows and $\mathrm{n}=2 \mathrm{t}(\mathrm{t}-1) /(\mathrm{p}-1)$ columns will form a balanced RM [t, 2t (t-1) / (p-1), p] when the entries of the array are filled in the following manner.

Let the elements of GF (t) be obtained as $\alpha_{0}=0, \alpha_{1}=x^{0}, \alpha_{2}=x^{1}, \ldots . ., \alpha_{t-1}=x^{t-2}$, where $x$ is the primitive root of $G F(t)$ and hence $x^{t-1}=1$. Let the $p$ rows of the array $A$ be numbered as $1,2,3, \ldots \ldots, \mathrm{p}$ and the $\mathrm{n}=2 \mathrm{t}(\mathrm{t}-1) /(\mathrm{p}-1)$ columns be numbered as $0,1,2$, ......., (n-1).

Then the element of array $\mathrm{A}$ in ith row $(\mathrm{i}=1,2,3, \ldots \ldots, \mathrm{p})$ and 1 th column $(1=0,1$, $2, \ldots . . ., \mathrm{n}-1$ ) will be

$$
\left[\alpha_{\mathrm{i}}\right]\left[\alpha_{(\mathrm{k}-1)(\mathrm{p}-1)+1}\right]+\alpha_{\mathrm{j}}=\left[\mathrm{x}^{\mathrm{l}-1}\right]\left[\mathrm{x}^{(\mathrm{k}-1)(\mathrm{p}-1)}\right]+\alpha_{\mathrm{j}}
$$

where $1=(\mathrm{k}-1) \mathrm{t}+\mathrm{j} ; \mathrm{j}=0,1,2,3, \ldots . ., \mathrm{t}-1 ;$ and $\mathrm{k}=1,2,3, \ldots, \lambda_{1}$.

The array A is a balanced RM [t, 2t (t-1) / (p-1), p], where $\lambda_{1}=2(\mathrm{t}-1) /(\mathrm{p}-1)$ is an integer and $\lambda_{2}=2$ according to the definition of Hedayat and Afsarinejad (1975).

The construction method 3.2 is illustrated by following example 3.3

Example3.3. Let $\mathrm{t}=13$ and $\mathrm{p}=9, \lambda_{1}=3$ and $\lambda_{2}=2$. Then the above procedure produces balanced $\mathrm{RM}(13,39,9), \lambda_{2}=2$ and the design so obtained is reproduced in the Table 3.4

Table No. 3.4.: $\quad$ Balanced $R M(13,39,9), \lambda_{1}=3, \lambda_{2}=2$

\begin{tabular}{|c|c|c|c|c|c|c|c|c|c|c|c|c|c|c|c|c|c|c|c|}
\hline & \multicolumn{19}{|c|}{ Experimental Units } \\
\hline ¿ & 0 & 1 & 2 & 3 & 4 & 5 & 6 & 7 & 8 & 9 & 10 & 11 & 12 & 13 & 14 & 15 & 16 & 17 & 18 \\
\hline 1 & 1 & 2 & 3 & 5 & 9 & 4 & 7 & 0 & 12 & 10 & 6 & 11 & 8 & 9 & 10 & 11 & 0 & 4 & 12 \\
\hline 2 & 2 & 3 & 4 & 6 & 10 & 5 & 8 & 1 & 0 & 11 & 7 & 12 & 9 & 5 & 6 & 7 & 9 & 0 & 8 \\
\hline 3 & 4 & 5 & 6 & 8 & 12 & 7 & 10 & 3 & 2 & 0 & 9 & 1 & 11 & 10 & 11 & 12 & 1 & 5 & 0 \\
\hline 4 & 8 & 9 & 10 & 12 & 3 & 11 & 1 & 7 & 6 & 4 & 0 & 5 & 2 & 7 & 8 & 9 & 11 & 2 & 10 \\
\hline 5 & 3 & 4 & 5 & 7 & 11 & 6 & 9 & 2 & 1 & 12 & 8 & 0 & 10 & 1 & 2 & 3 & 5 & 9 & 4 \\
\hline 6 & 6 & 7 & 8 & 10 & 1 & 9 & 12 & 5 & 4 & 2 & 11 & 3 & 0 & 2 & 3 & 4 & 6 & 10 & 5 \\
\hline 7 & 12 & 0 & 1 & 3 & 7 & 2 & 5 & 11 & 10 & 8 & 4 & 9 & 6 & 4 & 5 & 6 & 8 & 12 & 7 \\
\hline 8 & 11 & 12 & 0 & 2 & 6 & 1 & 4 & 10 & 9 & 7 & 3 & 8 & 5 & 8 & 9 & 10 & 12 & 3 & 11 \\
\hline 9 & 9 & 10 & 11 & 0 & 4 & 12 & 2 & 8 & 7 & 5 & 1 & 6 & 3 & 3 & 4 & 5 & 7 & 11 & 6 \\
\hline
\end{tabular}




\begin{tabular}{|r|r|r|r|r|r|r|r|r|r|r|r|r|r|r|r|r|r|r|r|}
\hline \multicolumn{110}{|c|}{ Experimental Units } \\
\hline 19 & 20 & 21 & 22 & 23 & 24 & 25 & 26 & 27 & 28 & 29 & 30 & 31 & 32 & 33 & 34 & 35 & 36 & 37 & 38 \\
\hline 2 & 8 & 7 & 5 & 1 & 6 & 3 & 3 & 4 & 5 & 7 & 11 & 6 & 9 & 2 & 1 & 12 & 8 & 0 & 10 \\
\hline 11 & 4 & 3 & 1 & 10 & 2 & 12 & 6 & 7 & 8 & 10 & 1 & 9 & 12 & 5 & 4 & 2 & 11 & 3 & 0 \\
\hline 3 & 9 & 8 & 6 & 2 & 7 & 4 & 12 & 0 & 1 & 3 & 7 & 2 & 5 & 11 & 10 & 8 & 4 & 9 & 6 \\
\hline 0 & 6 & 5 & 3 & 12 & 4 & 1 & 11 & 12 & 0 & 2 & 6 & 1 & 4 & 10 & 9 & 7 & 3 & 8 & 5 \\
\hline 7 & 0 & 12 & 10 & 6 & 11 & 8 & 9 & 10 & 11 & 0 & 4 & 12 & 2 & 8 & 7 & 5 & 1 & 6 & 3 \\
\hline 8 & 1 & 0 & 11 & 7 & 12 & 9 & 5 & 6 & 7 & 9 & 0 & 8 & 11 & 4 & 3 & 1 & 10 & 2 & 12 \\
\hline 10 & 3 & 2 & 0 & 9 & 1 & 11 & 10 & 11 & 12 & 1 & 5 & 0 & 3 & 9 & 8 & 6 & 2 & 7 & 4 \\
\hline 1 & 7 & 6 & 4 & 0 & 5 & 2 & 7 & 8 & 9 & 11 & 2 & 10 & 0 & 6 & 5 & 3 & 12 & 4 & 1 \\
\hline 9 & 2 & 1 & 12 & 8 & 0 & 10 & 1 & 2 & 3 & 5 & 9 & 4 & 7 & 0 & 12 & 10 & 6 & 11 & 8 \\
\hline
\end{tabular}

\section{Construction of Extra-Balanced Minimal Repeated Measurements Designs}

\section{1: $\mathrm{RM}\left[\mathrm{t}, \mathrm{t}^{2} /(\mathrm{p}-1), \mathrm{p}\right], \lambda_{2}=1$}

For every $\mathrm{t}$ which is prime power, the design $\mathrm{RM}\left[\mathrm{t}, \mathrm{t}^{2} /(\mathrm{p}-1), \mathrm{p}\right], \lambda_{2}=1$ and $\mathrm{p}<\mathrm{t}$ can always be constructed where only one treatment in a sequence is occurring more than once.

Construction Method 4.1: First construct the balanced RM ( $\mathrm{t}, \mathrm{t}, \mathrm{t})$, the jth sequence of which is given by $\mathrm{C}_{0}+\alpha_{\mathrm{j}} \mathrm{E}_{\mathrm{t}, 1} \forall \mathrm{j}=0,1,2,3, \ldots \ldots \ldots,(\mathrm{t}-1)$ Where $\mathrm{C}_{0}$ is an initial column vector of t element as $C_{0}=\left[1=x^{0}, x^{1}, x^{2}, \ldots, x^{t-1}=1\right]^{\prime}, x$ is primitive root of GF $(t), \alpha_{j}$ jth element of GF (t) and $E_{t, 1}$ column vector of ones.

Let the number of periods $p$ of the required design be such that $t=0 \bmod (p-1)$. Now construct the extra-balanced RM $(\mathrm{t}, \mathrm{t}, \mathrm{t}+1)$ by introducing one more period in balanced $\mathrm{RM}(\mathrm{t}, \mathrm{t}, \mathrm{t})$ at $[(\mathrm{t}+3) / 2]$ th period in which same treatments applied as applied in the $[(t+1) / 2]$ th period and period number of all other succeeding periods of $R M(t, t, t)$ is increased by integer 1 while keeping their entries same as those of the corresponding balanced RM ( $t, t, t)$ and denote it as $[t x(t+1)]$ array, say A. Now form the arrays $R_{1}$, $R_{2}, R_{3}, \ldots \ldots ., R_{\lambda 1}$, each of order ( $\left.p x t\right)$ from the array $A$ in the following manner: $R_{1}$ is array consisting of $1^{\text {st }}$ to pth row of $A ; R_{2}$ is an array consisting of pth row to (2p-1)th row of $A ; R_{3}$ is an array consisting of $(2 p-1)$ th row to $(3 p-2)$ th of $A$ and in general $R_{i}$ is an array consisting of $[(i-1)(p-1)+1]$ th row for every $i=1,2,3, \ldots \ldots, \lambda_{1}$. Now the juxtaposition of arrays $R_{1}, R_{2}, R_{3}, \ldots \ldots \ldots, R_{\lambda 1}$ will be an extra-balanced minimal repeated measurement design i.e. $R M\left[t, n=t^{2} /(p-1), p\right], \lambda_{2}=1$. 
Shakeel Ahmad Mir

The construction method 4.1 is illustrates by the following example 4.1

Example 4.1: Let $\mathrm{t}=9, \mathrm{p}=4, \lambda_{1}=3$ and $\lambda_{2}=1$

Balanced RM $(9,9,9)$

\begin{tabular}{|c|c|c|c|c|c|c|c|c|c|}
\hline$\delta_{0}^{n}$ & \multicolumn{9}{|c|}{ Experimental Units } \\
\hline こ & 1 & 2 & 3 & 4 & 5 & 6 & 7 & 8 & 9 \\
\hline 1 & 1 & 2 & 0 & 4 & 5 & 3 & 7 & 8 & 6 \\
\hline 2 & 3 & 4 & 5 & 6 & 7 & 8 & 0 & 1 & 2 \\
\hline 3 & 7 & 8 & 6 & 1 & 2 & 0 & 4 & 5 & 3 \\
\hline 4 & 8 & 6 & 7 & 2 & 0 & 1 & 5 & 3 & 4 \\
\hline 5 & 2 & 0 & 1 & 5 & 3 & 4 & 8 & 6 & 7 \\
\hline 6 & 6 & 7 & 8 & 0 & 1 & 2 & 3 & 4 & 5 \\
\hline 7 & 5 & 3 & 4 & 8 & 6 & 7 & 2 & 0 & 1 \\
\hline 8 & 4 & 5 & 3 & 7 & 8 & 6 & 1 & 2 & 0 \\
\hline 9 & 1 & 2 & 0 & 4 & 5 & 3 & 7 & 8 & 6 \\
\hline
\end{tabular}

Extra-Balanced RM $(9,9,10)$

\begin{tabular}{|c|c|c|c|c|c|c|c|c|c|}
\hline$\frac{n}{0}$ & \multicolumn{9}{|c|}{ Experimental Units } \\
\hline & 1 & 2 & 3 & 4 & 5 & 6 & 7 & 8 & 9 \\
\hline 1 & 1 & 2 & 0 & 4 & 5 & 3 & 7 & 8 & 6 \\
\hline 2 & 3 & 4 & 5 & 6 & 7 & 8 & 0 & 1 & 2 \\
\hline 3 & 7 & 8 & 6 & 1 & 2 & 0 & 4 & 5 & 3 \\
\hline 4 & 8 & 6 & 7 & 2 & 0 & 1 & 5 & 3 & 4 \\
\hline 5 & 2 & 0 & 1 & 5 & 3 & 4 & 8 & 6 & 7 \\
\hline 6 & 2 & 0 & 1 & 5 & 3 & 4 & 8 & 6 & 7 \\
\hline 7 & 6 & 7 & 8 & 0 & 1 & 2 & 3 & 4 & 5 \\
\hline 8 & 5 & 3 & 4 & 8 & 6 & 7 & 2 & 0 & 1 \\
\hline 9 & 4 & 5 & 3 & 7 & 8 & 6 & 1 & 2 & 0 \\
\hline 10 & 1 & 2 & 0 & 4 & 5 & 3 & 7 & 8 & 6 \\
\hline
\end{tabular}

The array $R_{1}, R_{2}$ and $R_{3}$ each of order ( $4 \times 9$ ) are obtained from the Extra-balanced Repeated Measurements design RM ( 9, 9, 10 ), are as follows:

$\mathrm{R}_{1}$ array;

\begin{tabular}{|l|l|l|l|l|l|l|l|l|}
\hline 1 & 2 & 0 & 4 & 5 & 3 & 7 & 8 & 6 \\
\hline 3 & 4 & 5 & 6 & 7 & 8 & 0 & 1 & 2 \\
\hline 7 & 8 & 6 & 1 & 2 & 0 & 4 & 5 & 3 \\
\hline 8 & 6 & 7 & 2 & 0 & 1 & 5 & 3 & 4 \\
\hline
\end{tabular}


$\mathrm{R}_{2}$ array;

\begin{tabular}{|l|l|l|l|l|l|l|l|l|}
\hline 8 & 6 & 7 & 2 & 0 & 1 & 5 & 3 & 4 \\
\hline 2 & 0 & 1 & 5 & 3 & 4 & 8 & 6 & 7 \\
\hline 2 & 0 & 1 & 5 & 3 & 4 & 8 & 6 & 7 \\
\hline 6 & 7 & 8 & 0 & 1 & 2 & 3 & 4 & 5 \\
\hline
\end{tabular}

$\mathrm{R}_{3}$ array;

\begin{tabular}{|l|l|l|l|l|l|l|l|l|}
\hline 6 & 7 & 8 & 0 & 1 & 2 & 3 & 4 & 5 \\
\hline 5 & 3 & 4 & 8 & 6 & 7 & 2 & 0 & 1 \\
\hline 4 & 5 & 3 & 7 & 8 & 6 & 1 & 2 & 0 \\
\hline 1 & 2 & 0 & 4 & 5 & 3 & 7 & 8 & 6 \\
\hline
\end{tabular}

Now the juxtaposition of arrays $R_{1}, R_{2}$ and $R_{3}$ forms an extra-balanced minimal Repeated Measurements design as given in table 4.1.

Table 4.1: Extra-balanced minimal $\operatorname{RM}(9,27,4), \lambda_{2}=1$

\begin{tabular}{|c|c|c|c|c|c|c|c|c|c|c|c|c|c|c|c|c|c|c|c|c|c|c|c|c|c|c|c|}
\hline \multirow{2}{*}{$\frac{\tilde{z}}{0}$} & \multicolumn{27}{|c|}{ Experimental units } \\
\hline & 1 & 2 & 3 & 4 & 5 & 6 & 7 & 8 & 9 & 10 & 11 & 12 & 13 & 14 & 15 & 16 & 17 & 18 & 19 & 20 & 21 & 22 & 23 & 24 & 25 & 26 & 27 \\
\hline 1 & 1 & 2 & 0 & 4 & 5 & 3 & 7 & 8 & 6 & 8 & 6 & 7 & 2 & 0 & 1 & 5 & 3 & 4 & 6 & 7 & 8 & 0 & 1 & 2 & 3 & 4 & 5 \\
\hline 2 & 3 & 4 & 5 & 6 & 7 & 8 & 0 & 1 & 2 & 2 & 0 & 1 & 5 & 3 & 4 & 8 & 6 & 7 & 5 & 3 & 4 & 8 & 6 & 7 & 2 & 0 & 1 \\
\hline 3 & 7 & 8 & 6 & 1 & 2 & 0 & 4 & 5 & 3 & 2 & 0 & 1 & 5 & 3 & 4 & 8 & 6 & 7 & 4 & 5 & 3 & 7 & 8 & 6 & 1 & 2 & 0 \\
\hline 4 & 8 & 6 & 7 & 2 & 0 & 1 & 5 & 3 & 4 & 6 & 7 & 8 & 0 & 1 & 2 & 3 & 4 & 5 & 1 & 2 & 0 & 4 & 5 & 3 & 7 & 8 & 6 \\
\hline
\end{tabular}

\section{References}

1. Atkinson, G. F. (1966). Designs for sequences of treatments with carryover effects. Biometrics, 22, 292-309

2. Afsarinejad, K. (1983). Balanced repeated measurements designs. Biometrika, 70, 199-204.

3. Afsarinejad, K. (1989). Circular balanced repeated measurements design. J. Statist. Prob. Letters., 7, 3985-4027.

4. Afsarinejad, K. (1990). Repeated measurements designs- A review Comm. Statist. Theory, Math., 19(11), 187-189.

5. Bradley, J.V. (1958). Complete counterbalancing of immediate sequential effects in a Latin square design. J. Amer. Statist. Assoc., 53, 525-528.

6. Cochran, W.G and Cox, G. M. (1986). Experimental Designs, $2^{\text {nd }}$ Ed. Wiley, New York.

7. Constantine, G. and Hedayat, A. (1982). A construction of repeated measurements design with balanced residual effects. J. Statist. Plan. Infer., 6, 153-64.

8. Davis, A. W. and Hall, W. B. (1969). Cyclic change-over designs. Biometrika, 56, 283-93

9. Dey, A., Chawla, G. C. and Balachandran, G. (1995). Cyclic change over designs. J. Indian Statist. Assoc. 33, 71-76. 
10. Gharde, Y. (2007). A study on cross-over designs in the presence of first order residual effects. Unpublished M. Sc. Thesis, IASRI, New Delhi.

11. Gordon, B. (1961). Sequence in groups with distinct partial product. Pacific J. Math, 11, 1309-1313.

12. Hedayat, A. and Afsarinejad, K. (1975). Repeated measurements design I. In a Survey of Statistical Design and Linear Models, ed. (J. N. Srivastava Ed.) Amsterdam, North Holland: 229-242.

13. Hedayat, A. and Afsarinejad, K. (1978). Repeated measurements design II. The Annals of Statistics. 6(3), 619-628.

14. Hedayat, A. and Young (2004). Universal optimality for selected crossover designs. J. Amer. Statist. Assoc., 99, 461-466

15. Houston, T. P. (1966). Sequential counter balancing in Latin squares. Ann Math. Statist, 37, 741-743.

16. Iqbal, I. and Tahir, M. H. (2009). Circular strongly balanced repeated measurements designs. Communication in Statistics - Theory and Methods, 38, 3686-3696.

17. Iqbal, I., Tahir, M. H. and Ghazali, S. S. A. (2010). Circular first- and secondorder strongly balanced repeated measurements designs. Communication in Statistics - Theory and Methods, 39, 228-240.

18. Mendelsohn, N. S. (1968). Hamiltonian decomposition of the complete direct ngraph. Theory of graphs: Proc. of the colloquium held at Tihany, Hungry, Sept. 1966. (Edition by P. Erdos and G. Kantona), Amsterdam North Holland, 237241.

19. Mir, S. A., Virk, M. S and Bhat Bilal. (2005). Balanced Repeated Measurements Designs. SKUAST J. of Res., 7(2), 282-288.

20. Mir, S. A., Virk, M. S., Sidiquee, S. H. and Bhat, M. A. (2008). A series of Minimal Balanced Repeated Measurement designs. SKUAST J. of Res., 10(2), 278-284.

21. Mir, S. A., Virk, M. S and S. Maqbool. (2009). Repeated Measurement Designs for Two-crop System. International journal of Statistics and Management Systems. 4(1-2), 124-133.

22. Patterson, H. D. (1952). Construction of balanced for experiments involving sequence of treatments. Biometrika, 39, 32-48.

23. Patterson, H. D. \& Lucas H. L. (1962). Change-over design. North Carolina Agric. Exp. Tech. Bull., No. 147.

24. Sharma, V. K., Jaggi, S., and Varghese, C. (2003). Minimal balanced repeated measurement designs. J. Appl. Statist., 30(8), 867-872.

25. Stufken (1991). Some families of optimal and efficient repeated measurements designs. JSPI. 27, 75-83

26. Sheehe, P.R. and Brass, D. J. (1961). Latin squares to balance immediate residual and other order effects. Biometrics, 17, 405-414.

27. Varghese, C. and Sharma, V.K. (2000). On totally balanced change over designs. Jour Ind. Soc. Ag. Statistics, 53(2), 141-150.

28. Westlake, W.J. (1974). The use of balanced incomplete block designs for experiments involving sequences of treatments. Biometrika, 39, 32-48.

29. Williams, E. J. (1949). Experimental designs balanced for the estimation of residual effects of treatments. Aust. J. Sci. Res., 2, 149-164. 